
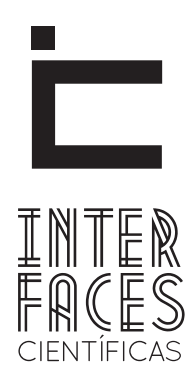

DIREITO

ISSN IMPRESSO 2316-3321

\title{
POĹTICAS PÚBLICAS E OS DIREITOS DAS COMUNIDADES TRADICIONAIS DE MATRIZ AFRICANA
}

\author{
PUBLIC POLICIES AND RIGHTS OF TRADITIONAL AFRICAN MATRIX COMMUNITIES \\ POLÍTICAS PÚBLICAS Y DERECHOS DE LAS COMUNIDADES TRADICIONALES DE LA MATRIZ AFRICANA
}

Ilzver de Matos Oliveira ${ }^{1}$

Ivonildon de Souza Santos ${ }^{2}$

\section{RESUMO}

Nesse artigo estabeleceremos um breve panorama estatístico da composição religiosa da população brasileira e das suas principais transformações nas últimas décadas, com o fito de localizarmos fundamentos para justificar se os atos de intolerância contra as religiões de origem africana advêm do racismo brasileiro e pensarmos sobre a necessidade de políticas públi- cas de garantia de direitos das comunidades tradicionais de matriz africana.

\section{PALAVRAS-CHAVE}

Religiões Afro-Brasileiras. Panorama Estatístico. Políticas Públicas. 


\section{ABSTRACT}

In this article we will establish a brief statistical overview of the religious composition of the Brazilian population and its main transformations in the last decades, in order to find grounds to justify if the acts of intolerance against the religions of African origin come from the Brazilian racism and think about the necessity Of rights-based pu- blic policies of traditional African-based communities.

\section{KEYWORDS}

Afro-Brazilian religions. Statistical overview. Public policy.

\section{RESUMEN}

En este artículo vamos a establecer un breve resumen estadístico de la composición religiosa de la población y su transformación importante en las últimas décadas, con el objetivo de localizar justificado que si los actos de intolerancia contra las religiones de origen africano provienen del racismo brasileño y piensan acerca de la necesidad políticas públicas de garantizar los derechos de las comunidades tradicionales de origen africano.

\section{PALABRAS CLAVE}

religiones afro-brasileñas; Resumen estadístico; Políticas públicas. 


\section{INTRODUCÃO}

0 fato de as religiões de origem africana conter tão emblematicamente a marca africana, muito mais que outras marcas advindas do sincretismo e da mistura com crenças de brancos e índios, têm motivado o movimento negro a buscar uma aliança com os terreiros para uma militância conjunta, porém, diz Prandi (1995, p. 125-126) que alguns sacerdotes afrorreligiosos,"sobretudo em São Paulo e no Rio de Janeiro, onde boa parte dos sacerdotes é de brancos, não desejam repor fronteiras raciais que a religião tem abandonado nas últimas décadas".

Esta análise, trazida por Reginaldo Prandi (1995) nos faz tomar alguns questionamentos cruciais para este texto: realmente hoje é impossível sustentarmos uma identidade racial do negro com os cultos de origem africana? As mudanças na composição religiosa da população brasileira arrefeceram os atos e a cultura de intolerância às religiões de origem africana e romperam com os ranços do período colonial e de escravização negra no Brasil?

A fim de encontrarmos algumas respostas para estas perguntas, estabeleceremos um breve panorama estatístico da composição religiosa da população brasileira e das suas principais transformações nas últimas décadas, com o fito de localizarmos fundamentos para justificar se os atos de intolerância contra as religiões de origem africana advêm do racismo brasileiro e pensarmos sobre a necessidade de políticas públicas de garantia de direitos das comunidades tradicionais de matriz africana.

\section{IDENTIDADE RACIAL E RELIGIOSIDADE AFRO-BRASILEIRA: PANORAMA ESTATÍSTICO DA COMPOSIÇ̃̃O RELIGIOSA DA POPULAÇÃO BRASILEIRA}

Inicialmente - analisando o estudo Novo Mapa das Religiões, coordenado por Marcelo Côrtes Neri no Centro de Políticas Sociais da Fundação Getúlio
Vargas (CPS/FGV) percebemos que a hegemonia da Igreja Católica tem passado, desde a década de 1990, por um forte processo de declínio. Por meio de processamento e análise dos dados publicados pelo Instituto Brasileiro de Geografia e Estatística (IBGE), a pesquisa constatou que em 1872 o catolicismo representava $99,72 \%$ da população brasileira, já em 2000 , trinta anos depois, houve uma queda significativa de $25,83 \%$. Tal retrato continuou a ocorrer, uma vez que o número de adeptos do catolicismo reduziu-se para $68,43 \%$ em 2009 (NERI, 2011, p. 7).

Em contraponto à religião católica, Neri (2011, p. 8) diz que o número de evangélicos cresceu consideravelmente nos últimos anos, de 1,0\% em 1890 para $20,23 \%$ em 2009. As religiões que não são católicas também apresentaram um crescimento, deixaram de ser $2,6 \%$ em 2000 para representar 4,62\% em 2009. Ou seja, diante da redução da hegemonia católica, o que se vê é uma maior diversificação de crenças religiosas e não uma redução da religiosidade brasileira, a qual permanece ativa.

Em uma visão internacional, dentre 157 países, o Brasil encontra-se no meio do ranking global quando o assunto é religiosidade ativa. O CPS/FGV, a partir do Gallup World Poll, verificou que cerca de $50 \%$ da população brasileira frequenta cultos religiosos de qualquer credo ${ }^{1}$. Trata-se de um País que eleva a religião a um status fundamental, característica mais comumente atrelada a países mais pobres, como os da África, do Sudeste Asiático e do sul da América do $\mathrm{Sul}^{2}$. (NERI, 2011, p. 14 e 15).

No que se refere ao sexo e a idade, a frequência dos cultos religiosos no Brasil se dá mais por mulheres $(57 \%)$ do que por homens (44\%), mais por pesso-

1 Ressalte-se que Neri (2011, p. 14), analisando a relação entre o PIB per
capta e a frequência a cultos religiosos, defende que não há qualquer cor-
relação entre esta frequência e nível de renda.
2 A pesquisa de Neri (2011, p. 15) mostrou que na comparação das nações,
o Brasil está em $60^{\circ}$ lugar com $89 \%$ de sua população acreditando que a
religião é importante e isso levou o autor a concluir que a religião hoje é um
"produto de exportação brasileiro, menos pela presença da Teologia da Li-
bertação católica e mais pela presença de grupos de evangélicos pentecos-
tais em outros países” (NERI, 2011, p. 16). Sobre o tema ver o conceito de
“Globalização da Teologia Política” ou “Globalização da Religião Política”
em Boaventura de Sousa Santos (2007, p. 25-27).

1 Ressalte-se que Neri (2011, p. 14), analisando a relação entre o PIB per relação entre esta frequência e nivel de renda.

2 A pesquisa de Neri (2011, p. 15) mostrou que na comparação das nações, de sua população acreditando que a "produto de exportação brasileiro, menos pela presença da Teologia da Lie mais pela presença de grupos de evangélicos pentecos“Globalização da Teologia Política” ou "Globalização da Religião Política” em Boaventura de Sousa Santos (2007, p. 25-27). 
as de idades avançadas (58\% pessoas de mais de 50 anos) do que por jovens ( $41 \%$ pessoas dentre 14 e 24 anos) (NERI, 2011, p. 15).

Outros dados importantes verificados por Neri (2007, p. 17) estão relacionados aos grupos sociodemográficos que deixaram de seguir a religião católica. Apesar de ter ocorrido uma queda do catolicismo em todas as faixas etárias, percebeu-se que as pessoas de idade mais avançada permaneceram, em sua maioria, seguindo a religião católica, ou seja, houve uma queda de apenas 3,29\% entre o período de 2003 a 2009. Enquanto isso, os grupos mais jovens tiveram uma queda em torno de 7,73\% dentro do mesmo recorte temporal. Ao acompanhar a trajetória religiosa de cada geração, o CPS/FGV percebeu que à medida que as pessoas ficam mais velhas tornam-se mais religiosas. Apenas 3\% das pessoas com 60 anos em 2009 eram sem religião (NERI, 2007, p. 18).

Como visto em linhas anteriores, o catolicismo tem se diluído e novas entidades religiosas têm ampliado seus espaços, principalmente as de origem evangélica, e nesse ponto a questão de gênero tem grande influência, pois, segundo Neri (2007, p. 19), "enquanto os homens abandonaram as crenças, as mulheres trocaram de crença, preservando mais que eles a religiosidade." Assim, em relação ao gênero, observamos nos dados da pesquisa que as mulheres são mais religiosas que os homens, porém estes são mais católicos que elas. Em dados estatísticos, $5 \%$ das mulheres não possuem religião contra $8,52 \%$ dos homens, porém apenas $71,3 \%$ das mulheres são católicas, enquanto $75,3 \%$ dos homens o são.

Desta forma, percebe-se então que o catolicismo possui raízes mais fortes entre os homens, porém a religiosidade possui maiores índices entre as mulheres. A religiosidade feminina também foi comprovada mediante dados da Pesquisa de Orçamentos Familiares (POF) 2008-2009/IBGE, a qual demonstrou que dentre 25 religiões analisadas, as mulheres predominavam em 23 delas. Apenas na religião Católica Apostólica Romana (68,32\% contra 67,38\%) e na Católica Apostólica Brasileira (0,48\% contra $0,47 \%)$ os homens tiveram participação maior do que as mulheres.
Uma das teorias levantadas por pesquisadores da FGV para justificar o impacto das transformações religiosas no Brasil foi a mudança do perfil feminino dentro da sociedade brasileira. Atualmente as mulheres são protagonistas não só nas atividades domésticas, mas também no mercado de trabalho. Tal revolução reflete significativamente no nível econômico, nos hábitos, nos costumes e crenças, e consequentemente na escolha da religião (NERI, 2011, p. 20-21).

0 estudo sobre os gêneros e mudanças nos grandes grupos religiosos, realizado pelo CPS/FGV com base no Censo Demográfico 1991-2000 e na POF 2009/IBGE, relevou que em 1991, o número de homens sem religião era de apenas 5,65\% contra 3,87\% das mulheres, todavia duas décadas depois, o número de homens sem religião passou para $8,52 \%$ contra $5 \%$ das mulheres. No que concerne aos religiosos, enquanto em 1991, as mulheres católicas chegavam a $83,31 \%$, em 2009 este número reduziu para $67,96 \%$. No caso dos homens, apesar da queda do catolicismo, esta foi menor, já que o número de católicos homens registrados em 2009 foi de $68,92 \%$.

Em relação às religiões alternativas (Evangélica Pentecostal, Evangélica, Espiritualista e outras), o aumento de adeptos masculinos ao longo dos anos foi reduzido, em comparação às mulheres. Por exemplo, os evangélicos pentecostais em 1991 eram representados por $4,99 \%$ da categoria masculina e $6,17 \%$ da categoria feminina; porém, em 2009 o número de adeptos desta religião dentre os homens aumentou para $11,28 \%$, enquanto que entre as mulheres a representatividade superou o dobro, chegando ao patamar de $14,17 \%$ (NERI, 2011, p. 21).

Outro ponto a justificar a evasão feminina do catolicismo dominante se dá em relação às características tradicionais da ética católica, a qual se mostra contrária à tendência emancipadora da mulher. Além disso, ao tratar sobre temas atuais envolvendo o divórcio, o aborto e o uso de contraceptivos, a Igreja Católica os considera impróprios e pecaminosos de acordo com os seus dogmas. Diante da revolução feminina experimentada, os tabus criados pela religião católica acabam por afastar as mulheres de suas crenças e cultos (NERI, 2011, p. 22). 
A partir da análise destes dados, fica latente que o mapeamento religioso em relação ao gênero encontra-se definido da seguinte forma: os homens são menos religiosos, entretanto, mais católicos, e aqueles que abandonaram o catolicismo migraram, em sua maioria, para a ausência de qualquer religiosidade. Noutro ângulo, as mulheres são menos católicas, todavia mais religiosas, uma vez que ao deixarem a religião católica, escolheram, em grande parte, a adoção de crenças alternativas. Sob outra perspectiva, passemos agora a analisar o mapeamento feito pela CPS/FGV em relação ao estudo da religião e da economia no Brasil.

No Brasil, segundo Neri (2011, p. 23-24), apenas $11,3 \%$ dos evangélicos são empregadores, sendo que a participação destas religiões na população é representada por 16,2\%. Fazendo uma análise comparativa entre nível de escolaridade e grupo religioso, o CPS/FGV constatou que a religiosidade tem menor intensidade nos extremos do campo educacional, ou seja, tanto os mais estudiosos, aqueles que possuem 12 anos ou mais de estudos, quanto os menos estudiosos, aqueles que possuem até três anos de estudos, demonstram índices elevados de ausência de religião, totalizando $7,46 \%$ e $7,27 \%$, respectivamente, no ano de 2009 .

Ainda no contexto educacional, observou-se também que os católicos e evangélicos pentecostais são formados por pessoas de nível educacional baixo. Em números quantitativos, dentre aqueles com até sete anos de estudos, $13,63 \%$ são evangélicos pentecostais e $69,68 \%$ são católicos. Em sentido contrário, os evangélicos tradicionais possuem adeptos com altos índices de escolaridade, posto que $8,7 \%$ destes possuem mais de oito anos de estudo.

No tocante às religiões com menor representatividade na sociedade brasileira percebe-se uma aderência de pessoas com alto nível de escolaridade (12 anos ou mais de estudo), os Espiritualistas com $6,04 \%$ e as outras religiões agregadas (incluindo os afro-religiosos, orientais e outras) com 4,19\%. 0 detalhamento do nível de escolaridade evidencia que as pessoas sem religião são formadas expressivamente por mestres e doutores (17,40\%). Em sentido contrário, os católicos são formados predominantemente por adultos alfabetizados (79,12\%), já os adeptos de outras religiões, tais como afro, orientais, dentre outras são formados por pessoas com nível tecnológico (9,42\%). Em outra ótica, os espiritualistas compreendem pessoas com especialização superior, mestrado ou doutorado em maior número $(6,95 \%$ e $6,96 \%$, respectivamente) (NERI, 2011, p. 24-25).

No tocante à classe social, o catolicismo possui mais adeptos nas camadas mais pobres $(72,76 \%$ na classe E), apesar de possuir representatividade dentre as classes elitistas (69,07\% nas classes AB). Em relação aos evangélicos, especificamente os pentecostais, possuem maior número de seguidores dentre as pessoas com pouca distribuição de renda (15,34\% na Classe D), mais do dobro da representatividade das classes de alta distribuição de renda (6,29\% nas classes $A B)$. As denominações espíritas possuem maioria de adeptos de classe social $A B(5,52 \%)$.

Em sentido semelhante, as religiões afro-brasileiras, no ano de 2009, possuíram maior aderência das classes sociais $A B(0,48 \%)$ e menor aderência da classe $E(0,16 \%)$. Os demonstrativos detalhados das denominações religiosas por classe socioeconômicas, em 2003 e 2009, demonstram que a religião Católica Apostólica Romana possuiu mais adeptos na classe $\mathrm{E}$ (76,75\% e $72,37 \%$, respectivamente). Em contrapartida, os espíritas possuíram mais aderência dos membros das classes AB (5,72\% e 5,25\%, respectivamente). Assim como os espíritas, as religiões de matriz africana encontraram maior adesão das pessoas enquadradas nas classes econômicas AB, com 0,34\% (Umbanda) e 0,13\% (Candomblé) (NERI, 2011, p. 24-31).

Em relação à distribuição de religiões por unidades federativas, a CPS/FGV constatou que os mais católicos são os nordestinos, com $74,9 \%$ de sua população, enquanto isso a região sudoeste representa a menor população católica, com $64,3 \%$ de sua população. No que diz respeito aos evangélicos, 0 Estado do Acre possui o maior número, dentre pentecostais e tradicionais, chegam a $36,64 \%$ de sua população. Dentre todos os Estados da Federação, Sergipe apresentou o menor número de evangélicos pentecostais, com apenas $4,75 \%$ da população. 
Todavia, com relação às religiões evangélicas mais tradicionais, o índice aumentou, encontrando-se na $19^{a}$ posição, com 5,95\%, conforme dados do POF 2009/IBGE analisados pelo CPS/FGV.

No tocante à população espiritualista, o Estado do Rio de Janeiro se mostrou com maior representatividade nacional, com o total de 3,37\% de adeptos. Em Sergipe os espiritualistas figuraram com $1,23 \%$ da população, assumindo, assim, a $10^{\mathrm{a}}$ posição. Porém, quando a religião analisada foi a afro-brasileira o quadro de representação mostrou-se bastante reduzido no Brasil. Em alguns Estados, como Roraima, Amapá e Tocantins não houve nenhum registro no ano de 2009. Exceto no Estado do Rio de Janeiro, com 1,61\%, os índices de adeptos de religiões de matriz africana por todo o país apresentou número inferior a 1\%. Já em Sergipe, assim como em vários Estados do Nordeste, 0 índice registrado em 2009 foi de apenas 0,06\%.

Sobre esse tema da declaração da sua religião entre os afro-religiosos, Prandi (2004, p. 225-226), ressalta que com a propagação das religiões afro-brasileiras pelo País foi possível identificar que quanto mais tradicionais os redutos pesquisados, mais os afro-brasileiros continuavam se declarando, e se sentindo, católicos. Assim, um mapeamento dos afro-brasileiros declarados nas diferentes regiões mostra que eles são em número relativamente pequeno no Nordeste, região em que a religião afro-brasileira tradicional se formou o que pode parecer paradoxal, e em número bem maior nas regiões em que se instalou mais recentemente, já no século XX, e onde a mudança religiosa no campo afro-brasileiro tem se mostrado mais vigorosa, casos do Sudeste e do Sul. Isso confirma que "até hoje o catolicismo é uma máscara usada pelas religiões afro-brasileiras, máscara que, evidentemente, as esconde também dos recenseamentos" (PRANDI, 2004, p. 225-226).

Em relação às religiões de origem oriental $e$ asiática, São Paulo foi o Estado que apresentou maior número de religiosos, com $0,78 \%$, seguido de 0,69\% no Rio de Janeiro e 0,52\% no Distrito federal. Não existindo em Sergipe, Rondônia e Paraíba nenhuma representatividade deste grupo religioso.
$\mathrm{Na}$ categoria outras religiões, Roraima aparece no $1^{\circ}$ lugar do ranking, com 6,17\%, estando o Amapá na última colocação, com $0,33 \%$. Na $8^{a}$ posição, Sergipe surge com 2,38\%.

A Fundação Getúlio Vargas também analisou as transformações religiosas nos últimos anos com foco nos grupos etários e os dados coletados corroboram o entendimento de que o catolicismo, dentre os anos de 2003 a 2009, apresentou queda acentuada, especialmente entre os jovens.

Outro aspecto a se destacar foi o aumento do número de pessoas que não professam nenhuma religiosidade, sendo os indivíduos entre 20 e 29 anos os que apresentaram maior alteração, passando de $6,12 \%$ para $8,87 \%$ entre os anos de 2003 e 2009. Os evangélicos foram os grupos religiosos que demonstram maior crescimento, principalmente entre os jovens (10 e 19 anos).

A partir deste breve apanhado das principais reflexões abordadas pelo "Novo Mapa das Religiões" produzido pela FGV em 2011, pode-se verificar, em âmbito nacional, uma perceptível diminuição da hegemonia católica, apesar do Brasil ainda ser o País mais seguidor do catolicismo no mundo. Esta redução do poderio da Igreja Católica, frente ao aumento de evangélicos, demonstra uma mudança de paradigma na religiosidade brasileira.

\section{COMPOSIÇÃO RELIGIOSA DA POPULAÇÃO SERGIPANA}

Em âmbito regional e local, os dados estatísticos demonstraram que Sergipe, apesar de possuir uma diversificação de religiões, ainda é um Estado de forte predomínio da Igreja Católica. Em 2009, 79,96\% dos sergipanos eram seguidores do catolicismo, índice que levou Sergipe ao $4^{\circ}$ lugar dentre todos os 27 Estados que compõem a federação. No Estado, apenas 5,58\% da população não profetizaram nenhum tipo de religiosidade.

No que concerne às religiões evangélicas, Sergipe é um Estado em que há mais religiões evangélicas tradi- 
cionais do que pentecostais. Já em relação às religiões espiritualista e afro-brasileira existe pequena representatividade local, neste último caso, o número de sergipanos que profetizam as religiões afro-brasileiras não chega a atingir o percentual de $1 \%$, sendo assim, resta patente a sua sub-representação estadual.

o Gráfico a seguir ilustra a distribuição da população sergipana, segundo a opção religiosa:

Gráfico 1 - Representatividade das Religiões em Sergipe

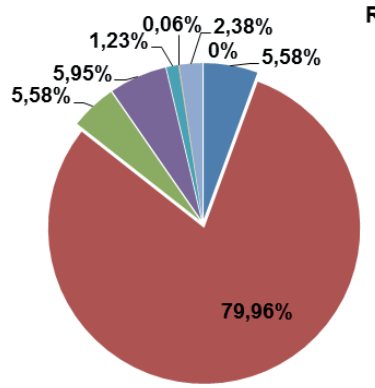

\section{Religiões em Sergipe - Ano 2009 \\ — Sem Religião \\ - Católica \\ - Evangélica Pentecostal \\ - Outras Evangélicas \\ Espiritualista \\ Afro-brasileira \\ Outras}

Orientais e Asiáticas

Fonte: CPS/FGV a partir de microdados da POF 2009 (IBGE).

Ao analisar os dados divulgados pelo Centro de Pesquisas Sociais da Fundação Getúlio Vargas acerca das Unidades Federativas, pode-se observar que Aracaju mostrou ser uma Capital majoritariamente Católica, com $72,26 \%$ dos aracajuanos, aderindo a esta religiosidade. Apenas, 7,64\% da população metropolitana, não possuíam qualquer tipo de religião em 2009.

Da mesma forma que ocorreu no Estado de Sergipe, em Aracaju a religiosidade evangélica tradicional possuiu mais representante que as pentecostais $(9,23 \%$ contra $4,18 \%)$. As religiões espiritualistas em Aracaju atingiram um pouco mais que $3 \%$, já as religiões de origem afro-brasileira foram as menos representadas no Estado, uma vez que apenas $0,11 \%$ dos aracajuanos profetizaram cultos e crenças de matriz africana.

Não existiu qualquer representação, em 2009, de religião de origem oriental ou asiática em Aracaju.
Gráfico 2 - Representatividade das Religiões em Aracaju

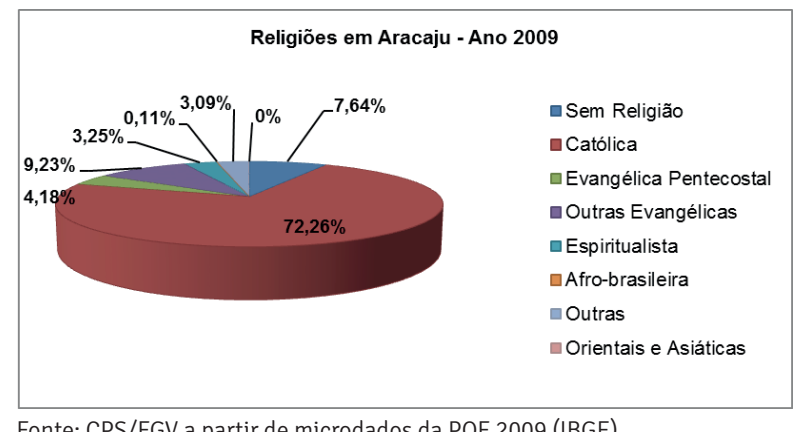

Fonte: CPS/FGV a partir de microdados da POF 2009 (IBGE).

Foi possível perceber, tendo como foco a análise em torno das religiões de matriz africana, que apesar de a religiosidade brasileira ter passado por um processo de diversificação e reestruturação, tendo o catolicismo perdido seguidores, as religiões de origem afro-brasileira permanecem na invisibilidade social, tanto nacional como local. Segundo o recenseamento de 2000 , apenas $0,3 \%$ da população brasileira adulta declaram-se pertencentes a uma das religiões afro-brasileiras, o que corresponde a pouco mais de 470 mil seguidores, embora pesquisas feitas com metodologia mais precisas indiquem valores maiores, da ordem de pelo menos o dobro das cifras encontradas pelo censo (PIERUCCI; PRANDI, 1996).

Após a análise dos dados do trabalho de Neri (2011) sobre os censos de 1991 e 2000 e da Pesquisa de Orçamentos Familiares de 2003 e 2009, analisaremos os dados do Censo de 2010, especificamente sobre o Estado de Sergipe e com foco nas religiões de origem africana, objeto da nossa investigação.

Segundo o Instituto Brasileiro de Geografia e Estatística (2010) Sergipe, atualmente com uma população em torno de 2.195.662 habitantes, é mesmo um Estado eminentemente católico, com elevada população evangélica e número considerável de pessoas que não professam nenhuma religião; analisando os dados sobre a população residente no Estado, verificamos que a sua população de católicos apostólicos romanos é de 1.579.4803, a de evangélicos é de 243.330 e 3 Outras denominações católicas também foram levantadas na pesquisa: os católicos apostólicos brasileiros são 5.394 e os católicos ortodoxos 509, o 
a dos evangélicos pentecostais é de 133.6574, sendo a população dos sem religião de 177.620 (INSTITUTO..., 2010).

Quando falamos de religiões de origem africana5 temos 4.371 seguidores de religiões afro-brasileiras, distribuídos da seguinte forma:

- 1.535 da umbanda;

- 2.780 do candomblé; e,

- 56 de outras declarações de religiosidade afro-brasileira.

Os espíritas são representados por 22.266 adeptos, número 5 vezes maior do que aqueles autoidentificados como afrorreligiosos.

Sobre este dado estatístico vale lembrar o que alerta Prandi (2004, p. 225-227) em relação a como alguns adeptos do candomblé e umbanda acabam se identificando como espíritas ou católicos para fugir da discriminação. Para o autor, no candomblé, sobretudo entre os mais "puros" ou tradicionais, alguns adeptos se denominam católicos ou até mesmo espíritas, como uma máscara para fugir do preconceito. Na umbanda, por sua vez, que já foi denominada por alguns de espiritismo de umbanda, também não é incomum, ainda atualmente, os umbandistas se chamarem de espíritas ou até mesmo de católicos.

Com o tempo, as religiões afro-brasileiras tradicionais se espalharam pelo Brasil todo, passando por muitas inovações, mas quanto mais tradicionais os redutos pesquisados, mais os afro-brasileiros continuam se declarando, e se sentindo, católicos. Mais perto da tradição, mais católico. Um mapeamento dos afro-brasileiros declarados nas diferentes regiões mostra isso muito bem: eles são em número relativamente pequeno no Nordeste, região em que a religião afro-brasileira tradicional se formou, o que pode parecer paradoxal, e em número bem maior nas regiões em que se instalou mais recente-

que ampliaria o percentual de denominados católicos no Estado de Sergipe para 1.580.583 adeptos.

4 Em Sergipe as denominações com maior representatividade no total da população segundo o Censo de 2010 são a Assembleia de Deus - 63.970 adeptos, a Universal do Reino de Deus - 13.302, a Congregação Cristã do Brasil - 10.354 e a Quadrangular - 9.338. Outras denominações pentecostais somaram 29.458 pessoas. Por sua vez, os Testemunhas de Jeová são 14.755 e os Mórmons 2.326, em Sergipe.

5 Os censos de 1991, 2000 e 2010 fornecem dados separados para a umbanda e o candomblé, sendo que a classificação candomblé reúne as chamadas religiões afro-brasileiras tradicionais (candomblé, xangô, tambor-de-mina, batuque). Além destas há a indicação de uma categoria chamada de "outras declarações de religiosidades afro-brasileiras". mente, já no século XX, e onde a mudança religiosa no campo afro-brasileiro tem se mostrado mais vigorosa, casos do Sudeste e do Sul. Até hoje o catolicismo é uma máscara usada pelas religiões afro-brasileiras, máscara que, evidentemente, as esconde também dos recenseamentos. Por sua vez, a umbanda é igualmente problemática quando se trata de quantificar seus seguidores. No início, a nova religião denominou-se espiritismo de umbanda, e não é incomum, ainda atualmente, os umbandistas se chamarem de espíritas, quando não de católicos. A umbanda conservou do candomblé o sincretismo católico: mais que isto, assimilou preces, devoções e valores católicos que não fazem parte do universo do candomblé. $\mathrm{Na}$ sua constituição interna, a umbanda é muito mais sincrética que o candomblé. (PRANDI, 2004, p. 225-226).

Para Prandi (2004) esse quadro de subnotificação da religiosidade de origem africana se deve a aspectos históricos relacionados ao estabelecimento do catolicismo como crença oficial e à perseguição empreendida contra essas religiões, sobretudo pelos órgãos de segurança pública do Estado, mas, também, às perseguições presentes, segundo o autor, advindas um pouco menos dos órgãos policiais e mais das religiões pentecostais brasileiras:

Quando se trata das religiões afro-brasileiras, as estatísticas sobre os seguidores costumam oferecer números subestimados, o que se deve às circunstâncias históricas nas quais essas religiões surgiram no século XIX, quando o catolicismo era a única religião tolerada no País, a religião oficial, e a fonte básica de legitimidade social. Para se viver no Brasil, mesmo sendo escravo, e principalmente depois, sendo negro livre, era indispensável, antes de mais nada, ser católico. Por isso, os negros que recriaram no Brasil as religiões africanas dos orixás, voduns e inquices se diziam católicos e se comportavam como tais. Além dos rituais de seu ancestrais, freqüentavam também os ritos católicos. Continuaram sendo e se dizendo católicos, mesmo com o advento da República, no fim do século XIX, quando o catolicismo perdeu a condição de religião oficial e deixou de ser a única religião tolerada no país. [...] Até recentemente, essas religiões eram proibidas e, por isso, duramente perseguidas por órgãos oficiais. Continuam a sofrer agressões, hoje menos da polícia e mais de seus rivais pentecostais, e seguem sob forte preconceito, o mesmo preconceito que se volta contra os negros, independentemente de religião. Por tudo isso, é muito comum, mesmo atualmente, quando a liberdade de escolha religiosa já faz parte da vida brasileira, muitos seguidores das religiões afro-brasileiras ainda se declararem católicos, embora sempre haja uma boa parte que declara seguir a religião afro-brasileira que 
de fato professa. Isso faz com que as religiões afro-brasileiras apareçam subestimadas nos censos oficiais do Brasil, em que o quesito religião só pode ser pesquisado de modo superficial. (PRANDI, 2004, p. 224-225).

Ao comparar os dados do Censo de 2010 com os levantamentos da pesquisa de Neri (2011), podemos perceber um aumento percentual considerável dos adeptos das religiões afro-brasileiras em Sergipe. Se antes elas representavam em torno de $0,06 \%$ da população do Estado hoje ela chega a quase $0,2 \%$, o que indicaria um aumento de um pouco mais de três vezes em 10 anos.

Gráfico 3 - Principais religiões em Sergipe - 2010.

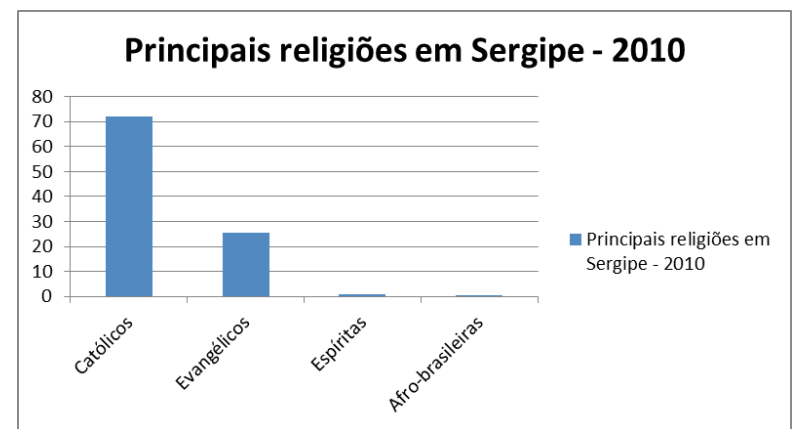

Fonte: Censo Demográfico 2010 (IBGE).

\section{POLÍTICAS PÚBLICAS, DIREITOS E IDENTIDADE AFRORRELIGIOSA}

Quais as causas e os efeitos deste crescimento do número de afrorreligiosos no conjunto da população brasileira? Como eles podem nos auxiliar como elementos para responder às nossas questões deste estudo? Esse aumento percentual implica em ampliação real no número de seguidores das religiões de matriz africana? Como esses dados impactam nas políticas públicas de garantias de direitos?

Inicialmente, em Prandi (2004, p. 226), encontramos duas possíveis causas para o crescimento das cifras de

6 Temos atualmente segundo o Censo de 2010 uma população de $0,12 \%$ de adeptos do candomblé e $0,07 \%$ de adeptos da umbanda. adeptos declarados do candomblé e da umbanda de um censo para outro: primeiro, os números refletiriam um aumento real no número de seguidores; segundo, a expansão da liberdade de crença no Brasil que como consequência fez com que muitos adeptos do candomblé e da umbanda se declarassem de religião afro-brasileira.

Assim, segundo o autor, os números crescentes mostrariam que as religiões de matriz africana crescem porque têm mais fiéis ou porque uma parcela maior dos antigos seguidores passa a se declarar abertamente, diante da nova conjuntura constitucional, legal e política, que englobou inclusive a criação da Secretaria de Políticas de Promoção da Igualdade Racial da Presidência da República em 2003, uma das apoiadoras da Campanha "Quem é de Axé diz que é!", realizada em decorrência do Censo de $2010^{7}$, e de políticas públicas específicas para as comunidades tradicionais de terreiro ${ }^{8}$, bem como de uma série de

7 Durante o período de preparação e de realização do Censo de 2010 o Coletivo de Entidades Negras (CEN), o Centro de Tradições Afro-Brasileiras (CETRAB), o Instituto Pedra de Raio, o Núcleo Religiões de Matriz Africana da Polícia Militar (NAFRO), a FORMA, o Centro de Integração da Cultura Afro-Brasileira (CIAFRO), a Associação AFA, o Forum Religioso Permanente Afro-Brasileiro do DF e Entorno (FOAFRO), o Movimento Nação Bantu (MONABANTU), a Coordenação Amazônica de Religiões Africanas e Ameríndias (CARMAA), o Instituto Nacional da Tradição e Cultura Afro-Brasileira (INTECAB), a Rede de Religiões Afro-Brasileiras e Saúde, a Congregação em Defesa das Religiões Afro (CEDRAB), a Federação Nacional do Culto Afro-Brasileiro (FENACAB), com o apoio da Secretaria Especial de Políticas de Promoção da Igualdade Racial (SEPPIR) e da Superintendência de Direitos Individuais, Coletivos e Difusos (SUPERDIR) da Secretaria de Estado de Assistência Social e Direitos Humanos promoveram nacionalmente a campanha “Quem é de Axé diz que é!", como forma de estimular a autodeclaração da religiosidade afro-brasileira. A Campanha "Quem é de Axé diz que é" teve como objetivo a autoidentificação dos adeptos das religiões de matriz africana para o Censo de 2010, corrigindo os números divulgados no último censo 2000 , onde os indicadores apontaram uma queda abrupta com relação à população de Umbanda e Candomblé ( $0,3 \%$ da população brasileira). 80 Decreto 6.040 de 7 de fevereiro de 2007 instituiu a Política Nacional de Desenvolvimento Sustentável dos Povos e Comunidades Tradicionais tendo como principal objetivo promover o desenvolvimento sustentável dos Povos e Comunidades Tradicionais, com ênfase no reconhecimento, fortalecimento e garantia dos seus direitos territoriais, sociais, ambientais, econômicos e culturais, com respeito e valorização à sua identidade, suas formas de organização e suas instituições. Estavam abrigados sobre a proteção desta lei as comunidades quilombolas, os povos ciganos e as comunidades tradicionais de matriz africana, conceituadas como: comunidades tradicionais de matriz africana constituem espaços próprios de resistência e sobrevivência, que possibilitaram a preservação e recriação de valores civilizatórios, de conhecimentos e da cosmovisão trazidos pelos africanos, quando transplantados para o Brasil. Caracterizam-se pelo respeito à tradição e aos bens naturais; o uso do espaço para a reprodução social, cultural e espiritual da comunidade; e a aplicação de saberes tradicionais transmitidos por meio da oralidade. 
políticas públicas direcionadas à população negra, como as cotas raciais na educação superior e no serviço público, as políticas de enfrentamento ao racismo institucional e à violência contra a juventude negra, entre outras.

Mas o fato é que em 1980 os autodeclarados afrorreligiosos representavam $0,6 \%$ da população brasileira residente. Em 1991, eles eram 0,4\% e em $2000,0,3 \%$. Em 2010 o percentual de 0,3\% se manteve, fato que foi festejado por setores das religiões de matriz africana, pois, tratava-se da primeira vez desde 1980 que este percentual não caía. Outros, como Prandi (2004, p. 226), entretanto, fazendo as contas do período de 1980 a 2000, reconheciam o declínio das religiões afro-brasileiras no Brasil e, lamentando, contabilizavam que nestas três décadas perderam aproximadamente 71 mil adeptos.

Figura 2 - Cartazes da Campanha "Quem é de Axé diz que é!"

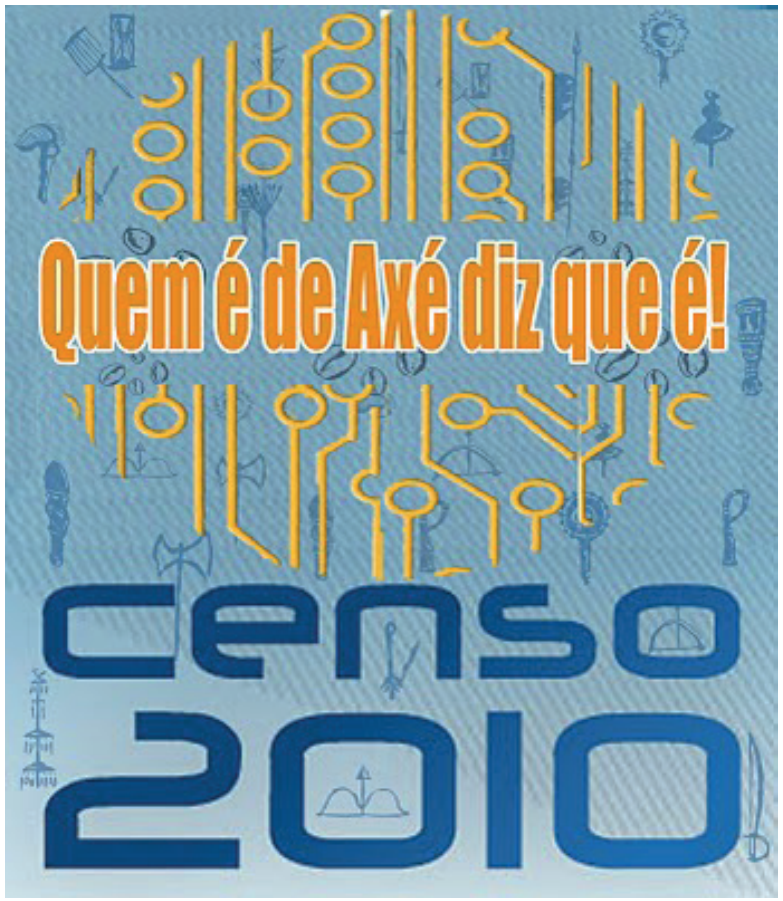

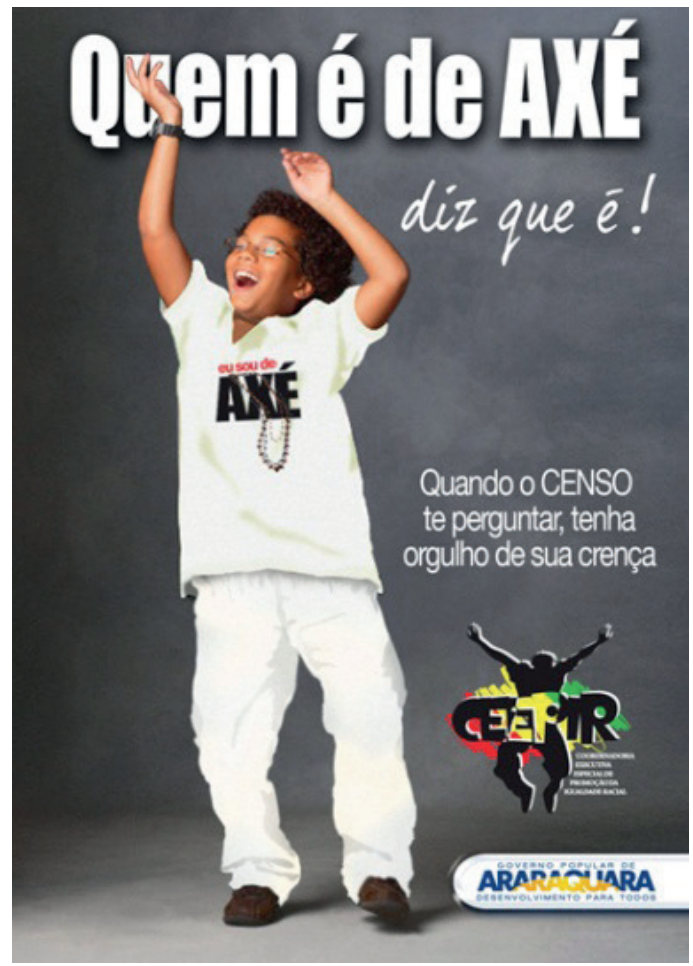

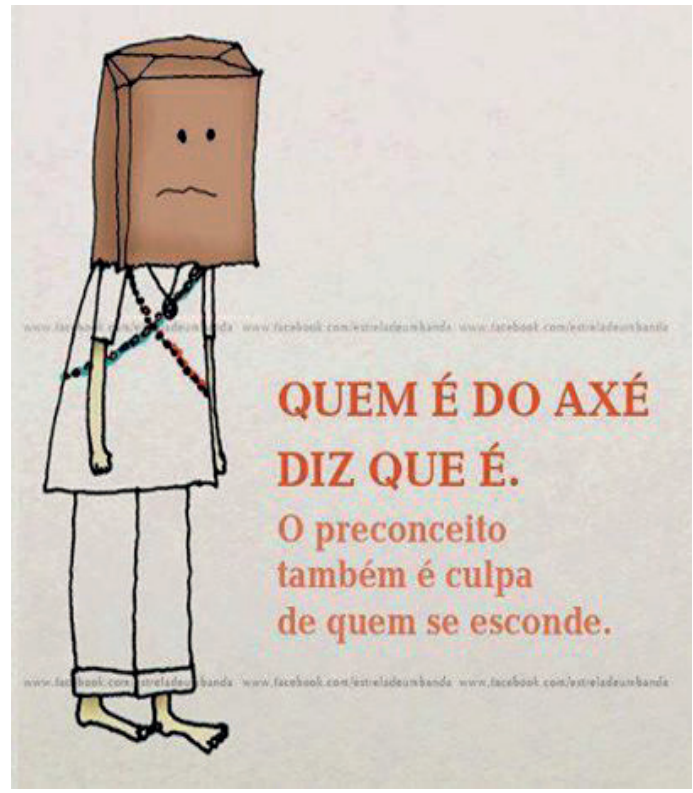




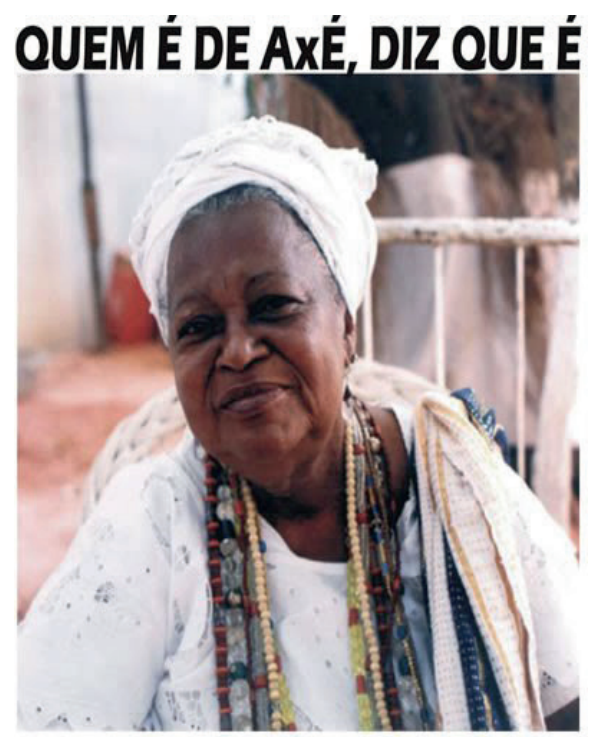

Neste Censo declare seu amor ao seu Orixá, diga que é do Santo, diga que é do Axé.

Pois quem é de Umbanda, quem é de Candomblé não pode ter vergonha, tem que dizer que é!
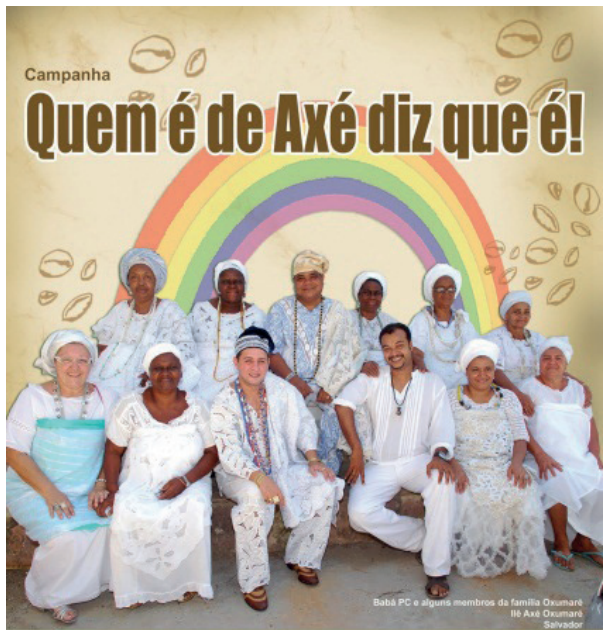

Em 2010, quando Censo vier, declare seu amor ao seu Orixá, diga que é do Santo, diga que é do Gunzu, diga que é do Axé. Poisquem é de Umbanda, quem é de Candomblé náo pode ter vergonha, tem que dizer que él

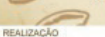

reen

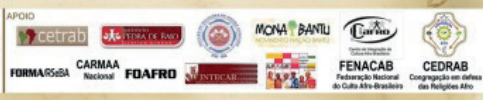

Fonte: Coletivo de Entidades Negras - CEN - cenbrasil.org.br
Ao refletir sobre as razões deste declínio, Prandi (2004, p. 26-27) levanta algumas hipóteses: primeiro, que elas estão associadas às novas condições da expansão das religiões no Brasil no contexto do mercado religioso ${ }^{9}$, que impõem mudanças que nem sempre religiões mais ajustadas à tradição, como são algumas religiões afro-brasileiras, conseguem assumir, tornando-se difícil para estas tanto os processos de atualização de suas práticas como o enfrentamento dos seus "concorrentes"; segundo, que o sincretismo católico que antes poderia até ser considerado um elemento positivo para a manutenção dos cultos de matriz africana, uma estratégia de resistência, hoje pode ser visto como um problema para a existência de tais cultos, pois se "o próprio catolicismo está em declínio, a âncora sincrética católica pode estar pesando desfavoravelmente para os afro-brasileiros, fazendo-os naufragar" (PRANDI, 2004, p. 227).

Em terceiro, que muitas igrejas neopentecostais têm crescido às custas das religiões afro-brasileiras e têm construído sua identidade mesmo na confrontação aos símbolos, liturgias e líderes das religiões de matriz africana; e quarto, que essa queda é devida ao segmento umbandista, que cai, enquanto sobe o número de adeptos do candomblé.

Como, pelo menos desde a década de 1950, a umbanda tem sido majoritária no conjunto afro-brasileiro, seu peso maior reflete diretamente na estatística geral do conjunto, indicando declínio. Mas a participação relativa do candomblé tem aumentado. Em 1991, o candomblé já tinha conquistado $16,5 \%$ dos seguidores das diferentes denominações de origem africana. Em 2000 , esse número passou a $24,4 \%$. O candomblé cresceu para dentro e para fora do universo afro-brasileiro. Seus seguidores declarados eram cerca de 107 mil em 1991 e quase 140 mil em 2000, o que representa um crescimento de $31,3 \%$ num período em que a população brasileira cresceu 15,7\%. Sem dúvida, um belo crescimento. Por outro lado, a umbanda, que contava com aproximadamente 542 mil devotos declarados em 1991, viu seu contingente reduzido para 432 mil em 2000. Uma perda enorme, de $20,2 \%$. E porque o peso da umbanda é maior que o do candomblé na compo-

9 Prandi (2004) denomina de "mercado religioso" a oferta de serviços que a religião é capaz de propiciar aos consumidores religiosos e as estratégias de acessar os consumidores e criar novas necessidades religiosas. 
sição das religiões afro-brasileiras, registrou-se para este conjunto nada mais nada menos que um declínio de 11,9\% numa só década. Na década anterior, fato para o qual Ricardo Mariano chamou a devida atenção (Mariano, 2001), as religiões afro-brasileiras já tinham sofrido uma perda de 4,5\%, declínio que não somente se confirmou como se agravou na década seguinte. 0 conjunto encolheu, mas o candomblé cresceu. (PRANDI, 2004, p. 227).

Esse quadro de crescimento do candomblé e declínio da umbanda pode ser registrado também no Censo de 2010, quando verificamos que o número de adeptos da umbanda que era de $432.000 \mathrm{em} 2000 \mathrm{tem}$ uma leve redução e passa para 407.331 em 2010, e que os adeptos do candomblé saem dos $140.000 \mathrm{em}$ 2000 para 167.363 em 2010 (INSTITUTO..., 2010).

Mas, além das mudanças no número de adeptos, uma das mais profundas alterações observadas nas religiões afro-brasileiras, sobretudo no candomblé, nas últimas décadas do século XX, "foi sua universalização, quando passou de religião étnica a religião de todos, com a incorporação, entre seus seguidores, de novos adeptos de classe média e de origem não africana" (PRANDI, 2004, p. 234-235). 0 autor, a partir de dados do censo demográfico do IBGE revela que apenas 16,7\% dos umbandistas se constituíam, no ano 2000, de pessoas que declararam ser de cor preta, contra $22,8 \%$ do candomblé.

Essa defesa de que as religiões afro-brasileiras têm perdido a sua identidade étnico-racial negra para se tornarem universais, entretanto, não se sustenta quando analisamos de forma mais completa os dados do Censo de 2010 e os comparamos com o seu antecessor de 2000. Os números mostram que diferentemente do que Prandi (2004) defende, o número de autodeclarados pretos tem crescido nas religiões de matriz africana. Atualmente na umbanda $17,4 \%$ dos seus adeptos são pretos enquanto que no candomblé este número sobe para $29,2 \%$, o que representa um aumento de mais de $7 \%$ em relação ao Censo anterior.

Além disso, se formos analisar na forma agregada os percentuais correspondentes aos grupos étnico-raciais preto e pardo, que juntos compõem a categoria racial dos negros, como trabalham o IBGE e os principais institutos de pesquisa brasileiros, percebemos que na umbanda o número de adeptos negros é de $45 \%$, enquanto o de brancos é de $54 \%$; já no candomblé, enquanto os brancos representam 30\% do total de adeptos, o número de negros corresponde a mais que o dobro, alcançando $68,5 \%$ do total de religiosos. E, por fim, reunindo umbanda e candomblé como as principais religiões de origem africana em nosso País, temos que dos 574.694 adeptos destes cultos, 297.988 são negros e 271.196 são brancos, o que em porcentagem significa que $51,8 \%$ dos afrorreligiosos são negros e $47,2 \%$ são brancos.

Gráfico 4 - Composição racial das religiões afro-brasileiras - 2010

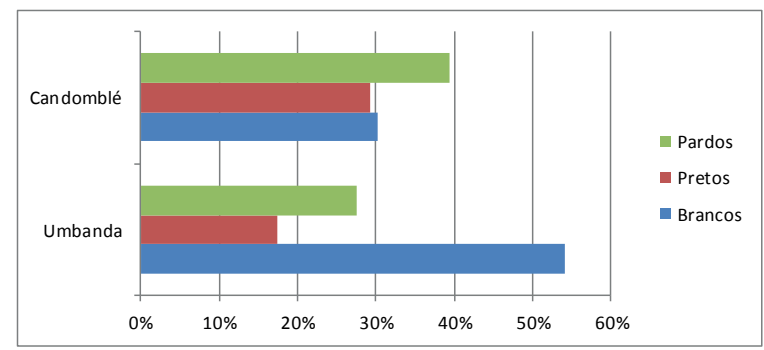

Fonte: Censo Demográfico 2010 (IBGE).

Em Sergipe, temos, em números absolutos, nas religiões candomblé e umbanda 919 adeptos identificados como brancos, 829 como pretos e 2.426 como pardos. Em percentuais, isso significa que do total de adeptos das religiões de matriz africana no Estado, 21\% deles são brancos, 19\% são pretos e $55,5 \%$ são pardos, as demais categorias raciais somam $4,5 \%$ (amarelos - 57 pessoas e indígenas - 140 pessoas). Seguindo a mesma linha, trabalhando com os dados agregados de raça, temos que em Sergipe, enquanto $21 \%$ da população de afrorreligiosos é formada por pessoas de pele denominada branca, $74,5 \%$ são negros, $6 \%$ acima do percentual nacional. 
Gráfico 5 - Composição racial das religiões afro-brasileiras em Sergipe - 2010

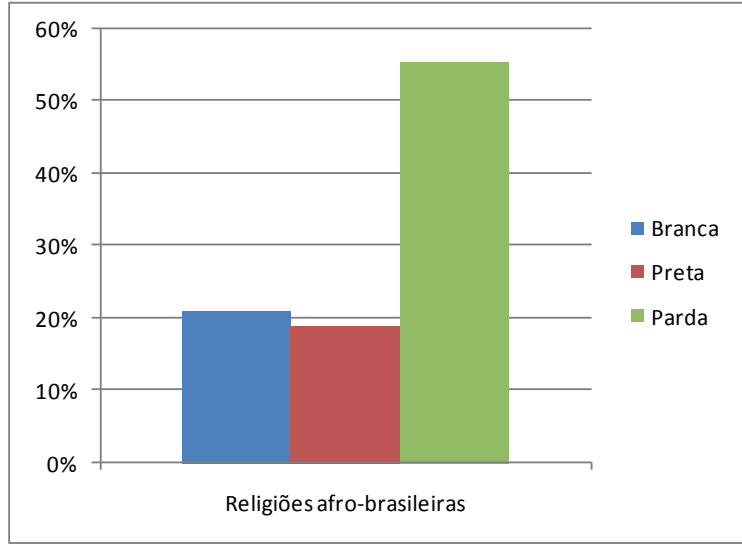

Fonte: Censo Demográfico 2010 (IBGE).

\section{CONCLUSÃO}

E então, retomamos nossas perguntas iniciais: realmente hoje é impossível sustentarmos uma identidade racial do negro com os cultos de origem africana? As mudanças na composição religiosa da população brasileira arrefeceram os atos e a cultura de intolerância às religiões de origem africana e romperam com os ranços do período colonial e de escravização negra no Brasil?

Com relação à primeira questão, podemos dizer que os dados levantados e aqui expostos a partir dos Censos Demográficos brasileiros, nos fornecem subsídios para acreditar que apesar de a presença de brancos e outras raças serem perceptível nos grupos religiosos de matriz africana, fruto de todo processo de universalização das religiões, eles são hoje predominantemente compostos por negros. Ou seja, além de trazerem a marca africana nas suas tradições rituais eles trazem também a marca negra na identidade étnico-racial da maioria dos seus seguidores.

Isso confirma que embora tenham transcorridos mais de 300 anos desde a vinda dos primeiros negros africanos para o Brasil, junto com suas tradições, língua e religiosidade, e apesar de estas marcas africanas te- rem se misturado com as trazidas pelos demais povos que construíram a nação brasileira, as análises sobre a religiosidade de matriz africana não permitem nem simbólica nem estatisticamente que afirmemos que elas na atualidade não são mais marcas identitárias do povo negro, africano e afro-brasileiro. De forma contrária, permite-nos afirmar a existência de uma total identidade do negro com os cultos de matriz africana no Brasil.

Sobre a segunda pergunta, se as mudanças na composição religiosa da população brasileira arrefeceram os atos e a cultura de intolerância às religiões de origem africana e romperam com os ranços do período colonial e de escravização negra no Brasil, a partir dos dados estatísticos aqui trazidos, percebemos que necessitamos de mais elementos para respondê-la, sobretudo um pouco do histórico e da situação atual de repressão aos afrorreligiosos em nosso país.

\section{REFERÊNCIAS}

INSTITUTO Brasileiro de Geografia e Estatística - IBGE.

Censo demográfico - 2010. Rio de Janeiro, 2010.

NERI, Marcelo Côrtes. Novo mapa das religiões.

Coordenação Marcelo Côrtes Neri. Rio de Janeiro:

FGV, CPS, 2011.

PIERUCCI, Antônio Flávio; PRANDI, Reginaldo. A realidade social das religiões no Brasil. São Paulo: Hucitec, 1996

PRANDI, Reginaldo. Raça e Religião. Novos Estudos Cebrap, n.42, São Paulo, abr-jun. 1995. p.113- 129.

PRANDI, Reginaldo. O Brasil com axé: candomblé e umbanda no mercado religioso. Estud. av. [on-line], v.18, n.52, 2004. p.223-238.

SANTOS, Boaventura de Sousa. Os direitos humanos na zona de contacto entre globalizações rivais,

Cronos, v.8, n.1, 2007. p.23-40. 
Data da submissão: 13 de novembro de 2016 Avaliado em: 10 de dezembro de 2016 (Avaliador A) Avaliado em: 02 de janeiro de 2017 (Avaliador B) Aceito em: 03 de janeiro de 2017
1 Doutor em Direito pela Pontifícia Universidade Católica do Rio de Janeiro - PUC-Rio; Mestre em Direito pela Universidade Federal da Bahia - UFBA; Professor Pleno do Mestrado em Direito da Universidade Tiradentes - UNIT Líder do Grupo de Pesquisa Direito Constitucional: sociedade, política e economia e vice-líder e pesquisador do Grupo de Pesquisa Políticas Públicas de Proteção aos Direitos Humanos - UNIT/CNPq; Editor-executivo da Revista Interfaces Científicas - Direito; Membro substituto da Câmara de Assessoramento e Avaliação da Fundação de Apoio à Pesquisa e à Inovação Tecnológica do Estado de Sergipe - FAPITEC/SE. Email: ilzver@gmail.com

2 Graduado em Marketing pela Universidade Salvador - UNIFACS. Email: nildo_ssa@hotmail.com 